\title{
La salvación como visión de Dios Aproximación en clave profética al concepto de salvación en san Ireneo de Lyon
}

\author{
LuIS MAURICIO AlBORNOZ OLIVARES \\ Universidad Católica del Maule (Chile) \\ malborno@ucm.cl
}

\begin{abstract}
Resumen
El Hijo, en cuanto Verbo, manifestó ya desde el Antiguo Testamento la revelación que acontecía progresivamente en la historia. Esta es la que culmina con la encarnación de la misma Palabra para seguir mostrando a Dios en la carne y llamarlo Padre. Ireneo de Lyon se esfuerza en proponernos que los escritos veterotestamentarios nos presentan en clave profética la visión, que en figura, resulta relevante para comprender la salvación otorgada por Dios. En efecto, los profetas del Antiguo Testamento entran por medio de la visión en la salvación. Ellos han participado ya de la visión de Dios, por lo que perfectamente acceden a las enseñanzas del Verbo. La Economía trinitaria de la salvación, que se entiende aquí como parte de un único designio, permite sostener esta afirmación y abrir camino, en clave del Lugdunense, a la misma Trinidad.
\end{abstract}

Palabras clave: Salvación, visión, profetismo, gnosticismo, participación, figura.

\section{Salvation as God's vision \\ Prophetic key approach to the concept of salvation in St Irenaeus of Lyon}

\begin{abstract}
The Son, as the Word, was already manifested in the Old Testament in the revelation that was occurring progressively in history. This is what culminates in the incarnation of the same Word and continues showing God in the flesh and calls him Father. St Irenaeus of Lyons proposes that the Old Testament writings offer a key to how the prophetic vision, that as figure, is relevant for understanding salvation that is given by God. Indeed, the prophets of the Old Testament enter into salvation by means of vision. They have participated in the vision of God, through which they access to the teachings of the Word. The Trinitarian economy of salvation, which is here understood as part of a unique purpose, permits sustaining this assertion and open a way, in accord with the Lyonese's interpretation, to the Trinity.
\end{abstract}

Key words: Salvation, vision, prophecy, Gnosticism, participation, figure.

Sacerdote de la Diócesis de Talca. Licenciado en Ciencias religiosas de la Universidad Católica del Maule y Magíster en Teología por la Pontificia Universidad Católica de Chile. Desde el año 2006 se desempeña como académico de la Facultad de Ciencias Religiosas y Filosóficas de la Universidad Católica del Maule, siendo su área de especialización la Teología Fundamental. Entre sus publicaciones destaca el libro ¿Cómo creer hoy en Dios?: elementos para una introducción a la fe cristiana (2008). 


\section{Introducción}

La obra de Ireneo de Lyon y el contexto que le tocó vivir nos presentan un panorama profundísimo de consideraciones y reflexiones en torno a la figura creyente de finales del siglo II. No estamos afirmando aquí una mera comprensión circunstancial que le haya llamado la atención al Lugdunense, sino que nos referimos concretamente al ser y al sentir creyente y eclesial de nuestro Santo. No figura la intención en él de salvaguardar convicciones o intereses personales, que se dejen ver en su obra, sino que prima aventajadamente el bien de la Iglesia. Esto se descubre en la fidelidad a aquello que la misma Iglesia desde el principio ha descubierto, proclamado y anunciado.

Lo anterior nos permite reconocer en Ireneo una magistral síntesis de la doctrina cristiana, su pretensión de salvaguardar la ortodoxia frente a las pretensiones gnósticas, nos abre camino a su reflexión y profundización. Evidentemente que la obra ireneana es inmensa y no podremos agotar aquí toda la dimensión cristológica, bíblica, eclesiológica o profética, que nuestro autor aborda en su trabajo. Más bien queremos llevar a cabo una aproximación que nos permita, al menos en parte, acercarnos a su pensamiento a través de alguna perspectiva particular.

Hemos considerado propicio, para estos efectos, sintetizar una aproximación a través del lenguaje profético que nos presenta nuestro autor, más aun, queremos reconocer a través de este camino una posibilidad de comprensión del mensaje de salvación que Ireneo muestra en clave profética. Por esta razón hemos llamado a esta breve aproximación «La salvación como visión de Dios». Bajo esta clave de lectura y reflexión, reconoceremos, al menos en parte, el trabajo de nuestro autor, y pretendemos, a su vez, acercarnos a su magna obra. Delimitamos así nuestro trabajo a esta afirmación que nos permite abrirnos paso, bajo clave de lectura, en el texto de Ireneo Adversus Haereses, y particularmente en el libreo cuarto ${ }^{1}$.

Si tuviésemos que centrar aun más nuestra mirada frente a esta obra de Ireneo, y dado el propósito de nuestra aproximación, tendríamos que solicitar el punto 20,5 del libro IV, pues aquí nos encontramos con un

1 Seguimos la edición crítica dirigida por Adelin Rousseau, IRÉNÉE DE LYON: Contre les Héresies, Livre IV. Éditions du Cerf, Paris 1965. Para algunas citas complementarias hemos utilizado la edición en español SAN IREREO DE LYON: Contra los Herejes. Exposición y refutación de la falsa gnosis. Edición preparada por C. I. González, en Revista Teológica Limense de la Facultad de Teología Pontificia y Civil de Lima, Vol. XXXIV, 2000. 
texto crucial respecto de nuestro tema. No obstante, habiendo otras referencias a las que pudiésemos dirigirnos, la teología que nos presenta Ireneo, en este apartado en particular, va dando cuenta progresivamente de la acción salvadora de Dios, y se percibe ciertamente su intención apologética. De este modo recurre en variadas ocasiones a explicar y explicitar el acontecimiento salvífico. Junto a este texto pudiese ser interesante, $y$ en algunos casos incluso necesarios en nuestra aproximación, recurrir a otros textos que en términos paralelos nos remiten a los temas que queremos profundizar ${ }^{2}$. Con todo, debemos afirmar que intentaremos seguir un esquema que facilite la comprensión de la síntesis abordada y con ello favorecer un diálogo transparente con nuestro autor. Más allá de nuestras reflexiones lo que interesa es que sea el mismo texto el que nos clarifique y nos proponga un camino, que nos permita descubrir con firmeza y claridad el significado de la salvación como visión de Dios.

\section{Salvación y visión: conceptos}

El inicio del libro IV de Adversus Haereses, parte con un breve prólogo que clarifica, desde su primer párrafo, la idea de refutar la falsa gnosis. Esto con el fin de lograr la salvación de aquellos que se encuentran en la herejía. Para ello enumera los principales puntos que aquí va a refutar ${ }^{3}$. En este contexto, ya desde el 1,1 su preocupación versará sobre la unidad de los dos testamentos. Punto que se extenderá en explícito desarrollo hasta el 11.1 de modo puntual, para luego a partir del 11,2 mostrar el Nuevo Testamento como plenitud del Antiguo Testamento. A partir del 19,1 el libro comienza a centrar el trabajo en la persona de Cristo como objeto último de toda la Escritura. En este contexto se circunscriben los principales hitos que desarrollamos en el presente artículo.

\footnotetext{
2 Como por ejemplo podríamos mencionar: 14,1: Seguir al Salvador es participar de la salvación; 20,6: Los hombres se harán inmortales por la visión; verán a Dios para vivir; 20,8: El ser humano verá a Dios con sus ojos y escuchará su voz; 20,9: Mediante la sabiduría de Dios... el ser bumano lo verá en aquel que será hombre en su venida.

3 «(...) afirman que el único Dios, Creador y Demiurgo, proviene del desecho. También blasfeman contra nuestro Señor, al dividir y separar a Jesús de Cristo, a Cristo del Salvador, al Salvador del Verbo y al Verbo del Unigénito. Y así como dicen que el Demiurgo es fruto del desecho, así también enseñan que Cristo y el Espíritu Santo fueron emitidos a causa de la penuria, y que el Salvador es producto de los Eones emitidos por la penuria. Como se ve, nada hay en ellos sino blasfemia», Adversus Haereses, Libro IV, Prólogo. En adelante Adv. Haer.
} 
A partir del 33,1 Ireneo dará cuenta de un modo más explícito la relación entre verdadera y falsa gnosis, y comenta los enunciados heréticos de las variadas corrientes marcionitas, ebionitas, valentinianos, entre otros. Una constante en todo el texto es la vinculación al rol profético que la Escritura revela. Ahora bien, ya hemos clarificado, en la introducción de este escrito, que hemos delimitado nuestro trabajo al Libro IV de la obra citada. En él nos hemos preocupado de identificar la fuerza de los conceptos que tocan nuestro tema, a saber, salvación y visión.

El concepto de «visión» lo encontramos fundamentalmente asociado a la figura divina o en referencia a Dios, y en esta referencia se nos sugiere de diversos modos. Veamos aquí algunas citas:

- 20,5. El Padre concede la incorrupción para la vida eterna, que a cada uno le viene con la visión de Dios ${ }^{4}$.

- 20,10. Habiendo tenido una visión de Dios (Ez 1,1), recordó los querubines, las ruedas y todo el desarrollo de ese misterio... Y después de narrar el resto de toda la visión del trono, para que nadie imaginase que había visto a Dios mismo, añadió: «Esta visión era semejante a la gloria del Señor» $(\mathrm{Ez} 1,28)^{5}$.

- 20,11. Después de esto, sobre una segunda visión en la que contempló al mismo Señor, escribió... ${ }^{6}$

- 32,2. Además, se les dio como una figura de los bienes celestiales, porque los seres humanos aún no eran capaces de soportar a ojo desnudo la visión de las cosas divinas?

Por cierto que las citas descritas no agotan la utilización y riqueza que el concepto de «visión» encuentra en la obra ireneana, pero aquí hemos querido destacar algunas de ellas que se nos presentan en relación a Dios y que favorecen la dirección que le vamos dando a nuestro

$4 \quad$ Patre autem incorruptelam donante in aeternam vitam, quae unicuique euenit ex eo quod videat Deum.

$5 \quad$ Manifestius autem adhuc et per Ezechiel factum est quoniam ex parte dispositiones Dei, sed non ipsum nidebant prophetae proprie Deum. Hic enim Dei cum uidisset uisionem, et cherubim et rotas eorum et uniuersae progressionis eius mysterium cum retulisset, et similitudinem throni cum widisset super eos, et super thronum similitudinem quasi figuram hominis, et illa quidem quae erant super lumbos eius quasi figuram electri, quae autem deorsum quasi uisionem ignis, et reliquam uniuersam throni uisionem manifestans, ne quis putaret eum in his proprie uidisse Deum, intulit: Haec uisio similitudinis gloriae Domini.

6 Et post haec in secunda visione eundem Dominum videns...

7 (...) typum autem caelestium ostendens, quoniam nondum poterat homo per proprium uisum videre quae sunt Dei. 
trabajo. Por su parte, el concepto de «salvación»es mucho más fecundo en la obra:

- 6,7. Era preciso que todos dieran testimonio de la verdad, para la salvación (...) así como la salvación es una sola para todos los que creen en él ${ }^{8}$.

- 7,1. Por eso Simeón: Ahora dejas a tu siervo ir en paz, Señor, porque mis ojos han visto tu salvación que preparaste ante todos los pueblos... (Lc 2,29$32)^{9}$.

- 14,1. Ni nos mandó seguirlo porque necesitase de nuestro servicio, sino para procurarnos a nosotros mismos la salvación. Porque seguir al Salvador es lo mismo que participar de la salvación, así como seguir la luz es recibirla ${ }^{10}$.

- 20,12. No sólo usó el servicio de los profetas para anunciar de antemano y prefigurar la salvación futura, por medio de las visiones que veían y los discursos que predicaban, sino también a través de sus acciones ${ }^{11}$.

Con estas citas sólo hemos querido reconocer la relevancia que tanto la «visión» como la «salvación» juegan en la obra de Ireneo. Lo que hace pertinente nuestra mirada a estos conceptos es que en nuestra intención está el descubrir la comprensión de la salvación como visión de Dios, lo que nos exige un acercamiento y profundización, en la interacción de ambos conceptos y la profundización que ello solicita. De este modo llegamos al punto 20,5 del Libro IV. En este punto descubrimos cómo, tanto la salvación como la visión, ocupan un lugar central, y la clave profética que nos presenta responde precisamente a esta interacción de conceptos.

Por una parte, la «salvación» se constituye en torno al intercambio; recapitulación-visibilización, a través de la comunión con el Espíritu. Y por otra parte, la comunión posibilita la salvación, porque ellos «ven a

\footnotetext{
8 Oportebat enim ueritatem ab omnibus accipere testimonium [et esse iudicium], in salutem... et una salus omnibus credentibus in eum.

$9 \quad$ Propter quod et Simeon ex semine eius reimplebat gratulationem patriarchae et dicebat: Nunc remittis seruum tuum, Domine, in Pace, quoniam uiderunt oculi mei Salutare tuum...

10 Neque nostro ministerio indigens iussit ut eum sequeremur, sed nobis ipsis attribuens salutem. Sequi enim Saluatorem participare est salutem, et sequi lumen percipere est lumen.

11 Non solum autem per uisiones quae uidebantur et per sermones qui praeconabantur, sed et in operationibus usus est prophetis, ut per eos praefiguraret et praemonstraret futura.
} 
Dios» ${ }^{12}$. Así nuestro autor clarifica que el Antiguo Testamento nos dispuso el camino para la venida del Hijo, en clave profética ${ }^{13}$. El Nuevo Testamento nos presenta al hombre educado por el Hijo, que se prepara para recibir la gloria ${ }^{14}$. El Hijo consolida al hombre para que se eleve en su gloria, y en esta gloria contemple a su Señor, pues a Dios se le conoce a través del Verbo, ya que es imposible conocerlo en su grandeza ${ }^{15}$.

$\mathrm{El}$ «ven» de los profetas, entonces, necesitará en nuestra aproximación de una profundización en Ireneo para poder dar cuenta del sentido apologético del escrito. A ello agréguese que la salvación se une a la visión como conceptos recíprocos. La salvación como visión, nos presenta entonces varios desafíos en su comprensión que el Lugdunense nos llevará a clarificar. Lo que podemos señalar de momento, ya que se entiende con cierta certeza, es la profecía; comprendida aquí como la predicación de las cosas futuras, lo que garantizaba que Dios sería visto por los hombres. Esta visión que sugiere en Ireneo un contexto históricosalvifico, en unidad de los dos testamentos ${ }^{16}$, anticipa ya la acción salvíficotrinitaria que el Santo ofrece en el texto en cuestión. El problema que se presenta es que si esta visión trasmitía el ver a Dios y como consecuencia la salvación, parece contradictorio con la incognoscibilidad de Dios que se afirmaba en la misma Escritura, pues nadie verá a Dios y vivirá (Ex $33,20)$.

La problemática que se le genera a Ireneo no es entonces menor. Por un lado, la comprensión de la salvación que se topa, como ya hemos demostrado, con la visión; lo que bíblicamente parece ser, al menos, confuso. Por otro lado, tenemos la presión gnóstica, a la cual Ireneo claramente debe hacer frente. Aunque no resulta sencillo para el Lugdunenese clarificar todo este enunciado, no obstante, como veremos, irá progresivamente desarrollando su obra apologética.

12 (...) Spiritu quidem praeparante hominem in Filium Dei, Filio autem adducente ad Patrem, Patre autem incorruptelam donante in aeternam vitam, quae unicuique euenit ex eo quod uideat Deum (Adv. Haer. IV 20,5).

13 Nam prophetia est praedictio futurorum, hoc est eorum quae post erunt praesignificatio (IV 20,5).

14 (...) uisus autem et per Filium adoptiue (...) (Adv. Haer. IV 20,5).

15 Cfr. Adv. Haer. IV 20,1.

16 Hay que señalar que particularmente el Libro IV presenta como núcleo básico la contienda de San Ireneo con los gnósticos respecto de la unidad entre los dos Testamentos, que para el Santo refleja la continuidad de una misma Economía. Nono enim Testamento cognito et praedicto per prophetas, et ille qui illud dispositurus erat secundum placitum Patris praedi cabatur, manifestatus hominibus quemadmodum noluit Deus, ut possint semper proficere credentes in eum et per testamenta maturescere 'ad' perfectum salutis (IV 9,3). 


\section{Contexto inmediato del tema: situación antignóstica}

Ireneo venía desarrollando en el libro IV la idea de unidad de ambos Testamentos, afirmando una única economía de la salvación y circunscribiendo en ella la acción de un solo Dios y Padre. Como idea general hemos de saber que la intención de Ireneo es ante todo enfrentar las desviaciones gnósticas ${ }^{17}$ que pululaban en la época, su idea es salvaguardar la ortodoxia respecto de la falsa gnosis ${ }^{18}$. En este sentido parece necesario destacar que, a juicio de los gnósticos, el denominado demiurgo era Yahvé fabricador del mundo y de los hombres materiales (en todo caso, dentro de la doctrina gnóstica, si bien podemos encontrar concordancia, también reconocemos divergencias claras ${ }^{19}$ ).

Es importante aquí señalar esta afirmación gnóstica que mueve la clarificación posterior de Ireneo. En el Libro I, 19,2 el Santo de Lyon señala: «Me ha parecido necesario añadir aqui lo que enseñan - refiriéndose a los gnósticos- acerca de su Protopadre, que habría sido desconocido antes de la venida

17 El nombre de "gnóstico» viene de la palabra griega gnwsis que significa «conocimiento». Por tanto, gnóstico es quien adquiere un conocimiento especial y vive según él. Ireneo hablan de la gnosis en el sentido del conocimiento de Jesucristo obtenido por la fe: «la verdadera gnosis —escribe san Ireneo- es la doctrina de los Apóstoles» (IV 33). Ireneo fue el primero en designarlos de este modo viendo su origen en la herejía de Simón el samaritano (Hch 8,9-24), y dice que sus seguidores se propagaron por Alejandría, Asia Menor y Roma dando lugar a «una multitud de gnósticos que emergen del suelo como si de hongos se tratara» (I 29,1). De ellos, continua diciendo Ireneo, derivan los valentinianos (seguidores de Valentín) que son a los que él combate directamente. Explica tal abundancia y diversidad de sectas diciendo que «la mayoría de sus fautores - en realidad, todos- quieren ser maestros; se van de la secta que abrazaron y urden una enseñanza a partir de otra doctrina, y luego a partir de ésta surge todavía otra, mas todos insisten en ser originales y en haber hallado por sí mismos las doctrinas que de hecho se limitaron a compaginar» (I 28,1). Con todo, hay que señalar que hablamos de un grupo de sectas que - según Bouyer- tienen en común dos características, a saber: la afirmación de un dualismo radical entre el mundo de los cuerpos y el de los espiritus, y paralelamente entre los principios superiores que regian uno y otro; y por otro lado la pretendida revelación de una serie de emanaciones y de combinaciones que, a partir del Dios bueno y del principio del mal, este último más o menos extrañamente identificado con la materia, habrían producido el mundo actual; L. BOUYER: Diccionario de Teología. Herder, Barcelona 1983, 300.

18 Señalemos que, a juicio de los herejes, los profetas enunciaban simplemente lo que les inspiraba el demiurgo animal. No significaban en futuro, sino de presente, lo que les comunicaba Yabvé. El objeto de las profecías era el demiurgo, sus manifestaciones; A. ORBE: Teología de San Ireneo. Vol. IV, BAC, Madrid 1997, 286.

19 Esto, entre otras razones, por su carácter secreto, que daba pie a divergencias de doctrina que por ser secretas dificultaban una comprensión común. En todo caso clarifiquemos que al hablar de movimiento gnóstico estamos señalando una serie de denominaciones, entre las cuales destacan Valentín y sus seguidores, Marción y los marcionitas, ofitas, barbelognósticos, gnosticoí de Hipólito, setianos, cainitas, etc. 
de Cristo. Escogen textos de las Escrituras tratando de convencer a los escuchas, mostrando que nuestro Señor anunció a otro Padre distinto del Creador del universo, el cual, como bemos expuesto, blasfemando impiamente ellos dicen que sería fruto de la penuria. Isaias, en efecto, dijo: 'Israel no me conoció y mi pueblo no entendió' (Is 1,3); lo cual ellos retuercen para adaptarlo a su doctrina sobre el desconocimiento del Abismo invisible. Y lo que Oseas escribió: No se balla en ellos verdad ni conocimiento de Dios' (Os 4,1), ellos tratan de dirigir al mismo propósito. Y: No bay quien comprenda ni busque a Dios; todos erraron, se ban corrompido', se lo aplican al no conocimiento del Abismo. Y cuando Moisés dice: Nadie podrá ver a Dios y quedar con vida' $(\mathrm{Ex} 33,20)$, están ciertos de que se refiere a lo mismo» ${ }^{20}$.

Entonces queda claro - como señala Orbe- que para los gnósticos los profetas no veían al Invisible, verdadero Dios, sino a Yahvé dios de índole síquica, humanamente accesible ${ }^{21}$. El Santo de Lyon afirmaba las profecías como anuncio de los futuros misterios de Cristo. Pero sigamos profundizando en el discurso gnóstico ${ }^{22}$.

Uno de los exponentes del Gnosticismo del siglo II es Marción ${ }^{23}$. Su doctrina refleja con claridad el cuestionamiento que Ireneo realiza a la falsa gnosis. Marción sostiene que hay un dios malo, el demiurgo, que es el creador del mundo y de la materia, origen del mundo sensible y que es precisamente Yahvé, el dios justiciero y vengativo del Viejo Testamento, el que impuso aquella Ley intolerable a los judíos. El Dios bueno era desconocido de todos hasta que envió a Cristo como redentor, para que lo diera a conocer a los hombres ${ }^{24}$. De este modo, al rechazar tan fuertemente el Antiguo Testamento, se desacreditaba la acción profética que para Marción derivaba en la ignorancia ${ }^{25}$ : «habia sin duda entre los

20 Et Fabricatorem quidem a prophetis wisum dicunt, illud autem quod scriptum est: Nemo widebit Deum et uinet, de innisibili Magnitudine et incognita omnibus dictum nolunt.

21 A. ORBE: Teología de San Ireneo, 286.

22 Pues, como dijimos, éstos señalaban que por ser invisible el padre del universo, era otro el que los profetas veían. Ese otro, precisamente, era el demiurgo Yahveh; cfr. Ibíd., 286.

23 Existían puntos de contacto entre Marción y los gnósticos como son su enseñanza sobre la existencia de un Dios bueno y un Dios malo, y su identificación de la materia con el mal, lo que le llevaba también a condenar el matrimonio y a prohibirlo entre los bautizados. Pero Marción se diferencia también de éstos en que no participa de sus teorías sobre las emanaciones de eones y sus relaciones con cosmogonías complicadas, y en que no habla de la importancia de la gnosis para la salvación ni de las divisiones de los cristianos en pneumáticos y psíquicos.

24 A. ORBE: Estudios sobre la teología cristiana primitiva. Ciudad Nueva, Madrid 1994, 642.

25 Estas son algunas afirmaciones que se deducen de la visión marcionita, que tiene gran repercusión en el gnosticismo de la época, agréguese que en su obra Antítesis, de la que sólo quedan fragmentos. Decía también que Cristo no se encarnó realmente, pues si su cuerpo hubiera sido verdadero habría estado bajo el poder del demiurgo, el 
profetas del Antiguo Testamento vaticinios divalentes, que excedian su común inspiración (demiúrgico); y ocultaban nueva inspiración: ¿de la sabiduría del Hijo, como estimaban los ofitas y valentinianos; o del Hijo mismo del Dios bueno, que adelantaba elementos de su primera Parusía?»)

No obstante, la más importante de las corrientes gnósticas del siglo II fueron los seguidores de Valentín. Estos aceptaban el canon ecuménico del Nuevo Testamento y su uso fue íntegro. No rechazaban el Antiguo Testamento (como Marción), pero lo recibían con diferentes acepciones $^{27}$. Tenían un planteamiento platónico, derivando en la afirmación que solo la gnosis es la que salva, de este modo no puede, en los valentinianos, tener cabida una comprensión salvadora armónica ni mucho menos, ni siquiera - como aclara Orbe- habrá posibilidad para los valentinianos de conocer al Padre a través del Hijo, pues, «íbastará conocer la persona del Hijo para descubrir en ellas los misterios de Dios Padre? Lógicamente no. Una Sophia que tiene por objeto los tesoros del movimiento futuro, mas no los del Padre, manifiesta la creación tal como la ve el padre, mas no al propio Padre» ${ }^{28}$. Una curiosidad importante de los valentinianos es que su doctrina exotérica se adaptaba a la regla de fe eclesial y pasaban dentro del grupo de la iglesia en la ortodoxia, fue Ireneo precisamente quien puso mano en los escritos internos de la escuela y denunció su heterodoxia ${ }^{29}$.

Toda esta clase de afirmaciones gnósticas derivaban entonces en una serie de confusiones y distorsiones de la fe que iban poco a poco mellando el sentir eclesial y transformándose en un serio peligro para la ortodoxia cristiana naciente. Por supuesto, que en estos casos expuestos, no acaba todo el movimiento gnóstico, que dada su magnitud, es muy difícil de delimitar, no obstante me parece que se nos presentan aquí pistas notoriamente claras respecto de la situación gnóstica, que permiten comprender, de acuerdo a nuestra profundización, la respuesta del Obispo de Lyon.

Hasta aquí queda claro, que con la reticencia que había hacia el Antiguo Testamento de parte del gnosticismo, se desconfiara de su contenido. Por su parte, si Yahvé era el demiurgo, la visión profética se relacionaba con este demiurgo. Los profetas en su visión solo veían al

dios de lo material, y no habría podido redimir al hombre. Para mayor profundidad se puede consultar la obra recién citada de Orbe.

26 A. ORBE: Estudios sobre la teología cristiana primitiva, 672.

27 Esto se ratifica en un documento gnóstico, conocido como la Carta a Flora, escrita por un gnóstico llamado Ptolomeo, según atestigua Tertuliano. Véase J. MonTSERRAT ÁlvareZ: Los Gnósticos. Gredos, Madrid 1990, 56.

28 A. ORBE: Estudios sobre la teología cristiana primitiva, 174.

29 J. MONTSERrat Álvarez: Los Gnósticos, 58. 
demiurgo, del cual recibían inspiración para alcanzar sus enseñanzas, pero no veían, ni siquiera podían conocer a Dios Padre. Los profetas eran entonces quienes hablaban, veían, actuaban a impulsos del pneuma del demiurgo o conversaban con el creador o legislador. El tema se presenta, en la controversia gnóstica, bajo la posibilidad real que tiene todo hombre de ver a Dios ${ }^{30}$. Para el gnosticismo esto no se puede dar, pues «el Eón perfecto o Abismo no fue jamás conocido antes del descenso del Salvado hacia el Cristo de la economía ${ }^{31}$. Ireneo no discrepa de los gnósticos en salvaguardar la trascendencia divina, sino en la posibilidad de ver a Dios, cuestión que intentaremos profundizar más adelante. De momento parece necesario sintetizar que la afirmación gnóstica redunda en esta imposibilidad de los profetas de haber visto a Dios, ellos, dado lo anterior, sólo vieron al demiurgo. Todo esto tiene repercusiones soteriológicas, a saber: visión-salvación. A esta perspectiva queremos acercarnos en el apartado siguiente.

\section{La salvación como prioridad Ireneana}

En el texto precedente señalábamos que el interés del Lugdunense, al refutar la falsa gnosis a través de Adversus haereses, era la salvación de los que se encontraban en la herejía. Es decir, Ireneo muestra ante todo un fin soteriológico a través de su obra ${ }^{32}$. Más aún, Ireneo descubre en el hombre el objeto de la salvación de Dios, «tal es la razón por la que el Verbo se hizo hombre, y el Hijo de Dios, Hijo del hombre: para que el hombre al entrar en comunión con el Verbo y al recibir asi la filiación divina, se convirtiera en bijo de

30 En el planteamiento gnóstico los cuerpos están formados por dos tipos de substancias: la primera enteramente mala, (la materia, byle) porque nació de la pasión; la segunda (el alma o sustancia psíquica, psyche) sigue mezclada de pasión, pero al menos puede convertirse (Adv. Haer. III, 29,3). Los seres materiales (bylicor) nacen de la pasión y son insalvables: al final se quemarán con toda la tierra. Los psíquicos han brotado de la conversión (aunque no han quedado del todo libres de pasión): por ello son medianamente salvables (pueden llegar a la Región Intermedia del Demiurgo, también éste hecho de substancia psíquica), si es que observan los mandamientos y tomando su Cruz (de la purificación) se libran de las pasiones. Los seres espirituales (pneumatikoi), del que formarían parte los gnósticos, se salvan por naturaleza, luego ya son salvos y no pueden perderse (Adv. Haer. I, 5,4).

31 R. PolanCO: El concepto de profecía en la teología de San Ireneo. BAC, Madrid 1999, 8.

32 No se entienda aquí una afirmación absoluta, como diciendo que Adversus haereses sólo toca el tema de la salvación, pues muchos son los aspectos que podríamos destacar en la obra. Lo que si intentamos es apuntar a aquello que es factor propio de nuestra línea de investigación: como ya hemos dicho, la salvación y su clave profética. 
Dios $\rangle^{33}$. Esta intención de Ireneo incluye a los propios gnósticos, pues el obispo de Lyon intentará volverlos a la ortodoxia.

Se entiende, entonces, que el texto en cuestión destaca el valor salvífico de la única economía. La propia encarnación encuentra aquí su cometido, pues la justificación de la Palabra hecha carne tiene el objeto de salvarnos. Por lo demás, para Ireneo, esta pasa a ser la afirmación central de la fe cristiana, que proviene de la predicación apostólica según la Tradición. Ireneo ve en Cristo la total Revelación del Padre, no sólo en el Nuevo Testamento, sino también en el Antiguo: el Hijo es quien revela al Padre, pero también el Padre revela al Hijo, por medio del Hijo mismo. Este es el único plan de salvación de toda la historia, aunque más especialmente manifestado en la Encarnación ${ }^{34}$.

A esto tenemos que agregar que Ireneo va desarrollando, en los primeros capítulos del libro cuarto, esta comprensión de la economía de la salvación como una sola obra, que no tiene en su devenir distinciones o menoscabos que podrían permitir algún atisbo de error o confusión ${ }^{35}$. Es, más bien, la obra del Dios Trino, que él va a desarrollar ilustrando toda la Economía. Aquí cobra importancia el rol que el Lugdunense entrega y reconoce en cada persona divina, advirtiendo el papel que cada una de las personas juega en nuestra salvación ${ }^{36}$. Por esto atribuye la revelación de la Palabra de Dios a su Verbo y a su Espíritu y es este mismo Espíritu que bajó, descendió sobre Jesús. Esta afirmación se ve claramente expresada al afirmar que el Espíritu Santo nos conduce al Hijo, así como este es nuestro camino al Padre ${ }^{37}$. El Padre siempre actúa

33 Propter hoc enim Uerbum Dei homo, et qui Filius Dei est Filius hominis factus est, <ut homo>, commixtus Uerbo Dei et adoptionem percipiens, fiat filius Dei (Adv. Haer. III 19,1).

34 Et propter hoc dicebat discipulis Dominus: Non uos me elegistis, sed ego elegi uos, significans quoniam non ipsi glorificabant eum, sequentes eum, sed in eo quod sequerentur Filium Dei glorificabantur ab eo (Ad. Haer. IV 14,1).

35 Confusión que se generaba por las diversas teorías gnósticas, señalemos aquí las teoría de Valentín respecto de la salvación del hombre: El hombre espiritual se slavará (llegará a la perfecta gnosis en el Pléroma) gracias a la cimiente espiritual que lleva consigo. El hombre material no se puede salvar de ninguna manera pues la esencia material es radicalmente incapaz de salvación; cfr. J. MONSTERRAT ÁlvAREZ: Los Gnósticos, 127.

36 Quidam enim eorum videbant Spiritum propheticum et operationes eius in omnia genera charismatum effusa; alii uero aduentum Domini et eam quae est ab initio administrationem, per quam perfecit uoluntatem Patris quae est in caelis et quae est in terris; alii uero et glorias paternas temporibus aptas, et ipsis qui videbant et qui tunc audiebant et hominibus qui deinceps audituri erant. Sic igitur manifestabatur Deus: per omnia enim haec Deus Pater ostenditur, Spiritu quidem operante, Filio uero administrante, Patre vero comprobante, homine vero consummato ad salutem (Adv. Haer. IV 20,6).

37 Spiritu quidem praeparante hominem in Filium Dei, Filio autem adducente ad Patrem, Patre autem incorruptelam donante in aeternam uitam, quae unicuique euenit ex eo quod uideat Deum (Adv. Haer. 20,5). 
en unión con el Hijo al inspirar las Escrituras, ya que fueron dictadas por el Verbo de Dios y por su Espíritu. No obstante, la inspiración profética será obra del Espíritu, que tiene como objetivo revelar al Hijo ${ }^{38}$.

Tanto la economía histórica del Antiguo, como del Nuevo testamento se dirigen a disponer al humano plasma para la vista de Dios, es el Espíritu quien tiene la misión de que el plasma corpóreo, que no puede ver a Dios por sí mismo, se haga capaz de verlo y no sólo al Dios hombre, sino al propio invisible Dios. Es este mismo Dios quien dispone el humano cuerpo, venido del barro, para abrazar el espíritu del Padre, y eternizarse con él ${ }^{39}$. Es conclusión, todo va conduciendo a la acción salvífica de Dios si el hombre se dispone a acogerla.

\section{La comprensión del ver en un modo figurado (presignificatio)}

Ya hemos dicho que nuestro autor tiene una particular dedicación al problema de la salvación, toda la economía, dijimos, apunta al acontecimiento salvador. Sin embargo, esta salvación se descubre en la obra como ya acontecida en el Verbo. En el Antiguo Testamento como parte de una misma economía, esta salvación era vivida a modo de figura, esto es lo que anunciaban los profetas. Bajo esta clave profética Ireneo insistirá en que el autor de la Escritura es el único Dios, que ha hablado por su Verbo e inspirado a los escritores sagrados por medio de su Espíritu, el que habla puede ser tanto el Hijo como el Espíritu ${ }^{40}$. Es la acción salvadora que se va plasmando a través de las personas divinas. Son estas personas las que han actuado en toda la historia, por esto es posible que los profetas - que se caracterizaban por las profecías- hayan tenido la visión del Verbo, por lo que pudieron profetizar los misterios futuros ${ }^{41}$.

38 Recordemos que una de las afirmaciones mas categóricas de Ireneo, dado el contexto antignóstico, y en las cuales incorpora la acción del Espíritu, es la unicidad de Dios manifestada en la obra salvífica. Es el mismo Creador nuestro y Padre del Verbo que se manifiesta como el Hijo hecho carne. Signo de esta unidad es que Dios ha realizado toda su obra por el mismo Espíritu, por medio del cual al principio nos creó, en el Antiguo testamento anunció la salvación que debería realizar mediante la encarnación de su Hijo, y la llevó a cabo en cada uno de nosotros por la filiación que nos hace llamarlo ¡Abbá! en el Espíritu.

39 A. ORBE: Estudios sobre la teología cristiana primitiva, 363.

40 Sic igitur manifestabatur Deus: per omnia enim haec Deus Pater ostenditur, Spiritu quidem operante, Filio uero administrante, Patre uero comprobante, homine uero consummato ad salutem (Adver. Haer. 20,6).

41 Señalemos aquí que Ireneo combate la noción de los herejes. Según estos los profetas enunciaban simplemente lo que les inspiraba el demiurgo animal. 
Los gnósticos no podían reconocer esta misma afirmación, pues ellos negaban la unidad del Padre y del Hijo, que el Lugdunense afirmaba en el orden de la economía: es el mismo Padre del Verbo que se manifiesta en el Hijo hecho carne. Signo de esta unidad es que ha realizado toda su obra por el mismo Espíritu, esto es lo que hace posible la figura del Verbo que contemplaban los profetas. Para los gnósticos los profetas no veían al invisible, verdadero Dios, sino a Yahvé, dios de índole síquica, humanamente accesible; tampoco anunciaban en futuro la visibilidad del Verbo, Hijo del verdadero Dios; pues nada sabían del Verbo, anunciaban de presente lo que les comunicaba Yahvé: no significaban proféticamente ${ }^{42}$, sino presencialmente, los sentimientos del demiurgo ${ }^{43}$.

La intención del Santo de dar cuenta de la clara unidad de los dos Testamentos como parte de una misma economía, se ve reforzada aquí por esta comprensión prefigurada del Verbo a través de la profecía ${ }^{44}$. Si los profetas han podido contemplar al Verbo es porque forman parte de una misma economía ${ }^{45}$. Para Ireneo «no trataban con el Creador, según el invisible; sino con el Verbo, de quien prenunciaban, con significativas modalidades, primeramente, como base inicial 'el advenimiento en carne de Dios y hombre'» ${ }^{46}$. La figura de lo que vendrá, captada por los profetas, que son los que tienen el carisma profético, se ve claramente en el Libro IV de Adversus haereses. Ireneo señala que la profecía es el anuncio de las cosas futuras ${ }^{47}$, esto es la indicación adelantada (presignificatio) de esas cosas que iban a ocurrir después ${ }^{48}$.

\footnotetext{
42 Para el gnosticismo los profetas sirven al demiurgo, dios visible, de quien reciben directamente el mensaje. La profecía vendría a ser una revelación directa del «falso Dios» a hombres elegidos por él, no por los hombres; cfr. A. OrBE: Teología de San Ireneo, 287.

43 Ibíd., 286.

44 Los gnósticos, eliminando muchos elementos de la Escritura que no se ajustaban a sus doctrinas, aducían una tradición secreta, mistérica, reservada a los iniciados en la gnosis. Pero cada uno manejaba los contenidos según convenía a sus postulados. San Ireneo también acude a la Tradición, pero, por una parte, nunca la separa de la Escritura, y, por otra, la defiende como abierta a todos los pueblos y originada de los mismos Apóstoles. Jamás como secreta o reservada a iniciados. Esta Tradición se conserva intacta en toda la Iglesia, que la predica siempre fiel a sí misma; cfr. Adv. Haer. II 9,1 .

45 De hecho, «el Verbo, en cuanto encarnado, había de unir el fin al principio, el hombre a Dios. Antes de encarnarse se deja sentir entre los justos, otorgándoles el carisma profético»; A. ORBE: Estudios sobre la teología cristiana primitiva, 355.

46 Ibíd., 356.

47 Nam prophetia est praedictio futurorum, hoc est eorum quae post erunt praesignificatio (Adver. Haer. IV, 20,5).

48 R. POLANCO: El concepto de profecía en la teología de San Ireneo, 25.
} 
El planteamiento de Ireneo nos conduce con esto a la comprensión de la salvación en clave profética. Dada la relevancia histórica del acontecimiento salvífico que hemos profundizado, y que nuestro autor desarrolla particularmente en la primera parte del libro cuarto, nos prepara el camino para introducirnos en la dimensión profética. El ver de los profetas, que Ireneo explica, nos permite abrirnos camino en la línea de profundización que vamos siguiendo.

\section{La operación profética (video-visio)}

Con lo que ya hemos señalado podemos ahora permitirnos dar un nuevo paso. Ya adelantamos que los gnósticos afirman que los profetas no habrían visto realmente al único y verdadero Dios, sino sólo al creador del mundo ${ }^{49}$. Este es el punto que nuestro autor intentará refutar en la segunda parte del Libro $I^{50}$. ¿En qué consiste el «ver» de los profetas? Esto es lo que Ireneo va a profundizar en esta parte de su obra $^{51}$. Particularmente queremos centrarnos en el punto 20,5. ¿Qué significa «ver» en clave profética? Se nos presenta aquí una interesante propuesta ireneana que dada la situación antignóstica que plantea, nos abre a una perspectiva en la misma clave salvífica que viene siguiendo.

El sentido del ver profético se manifiesta en su carácter futuro, es decir, refutando la comprensión gnóstica. En Ireneo el tema son las cosas por venir, predicación de lo que será en el futuro, que evidentemente tienen un claro carácter salvífico, y esto para los profetas se sintetiza en que el hombre verá a Dios. La profecía entonces se enmarca en este anuncio, visión que otorga el Espíritu de profecía a los llamados profetas ${ }^{52}$.

La síntesis presentada por Ireneo en clave profética nos permite descubrir el mensaje salvífico que se plantea: el hombre verá en carne al invisible Dios y los profetas adelantan la visión futura de Dios por el hombre. Este es el eco que resuena en la predicación del Verbo

\footnotetext{
49 Ibíd., 9.

50 Entiéndase Adversus Haereses, IV, 20-35

51 Pues yendo más allá con el gnosticismo su teoría en este punto radica en que ni los profetas anunciaron, ni el Señor enseñó, ni los Apóstoles transmitieron. Y, sin embargo, ellos se gloriaban de haber recibido de estas cosas un conocimiento más elevado que todas las demás personas.

52 Et propterea prophetae, ab eodem Uerbo propheticum accipientes charisma, praedicauerunt eius secundum carnem aduentum, per quem commixtio et communio Dei et hominis secundum placitum Patris facta est, ab initio praenuntiante Uerbo Dei quoniam nidebitur Deus ab hominibus... (Adv. Haer. IV 20,4).
} 
encarnado: «Bienaventurados los limpios de corazón porque ellos verán a Dios» (Mt 5,8). La resolución de Ireneo no sólo pretende preanunciar el ver a Dios, sino que se reafirma también la visión armónica de la economía de la salvación, pues es el mismo ver, preanunciado proféticamente, el que acontece en los últimos tiempos (Gal 4,4).

Esta garantía del ver del Lugdunense se topa, como ya hemos señalado, con la dificultad que brota de la misma Escritura, ya que «nadie verá a Dios y vivirás ( $\operatorname{Ex} 33,20)$. Ireneo resuelve esta dificultad magistralmente, pues si bien el Padre resulta invisible en su grandeza y gloria, justamente es esa misma grandeza que refleja su amor infinito, al dejarse ver por aquellos que le aman, haciéndose ante ellos gratuitamente visible $^{53}$. Esto es lo que anunciaban los profetas pues, «lo que es imposible entre los hombres para Dios es posible». Frente a la magnitud e inmensidad de Dios se encuentra la dilectio humanitas, omnipotencia en su revelación a los hombres.

El ver que anunciaban los profetas no tiene relación con una capacidad humana connatural al ser del hombre, sino más bien, refleja la omnipotencia divina y su inconmensurable amor a la humanidad, es un don concedido por pura benevolencia de Dios, como señala Orbe, Dios se deja ver, en su amor al hombre, por aquellos que le aman. Esto es lo que vaticinaban los profetas: que los justos verían a Dios ${ }^{54}$. Con estas indicaciones que reflexionamos, a partir de la obra ireneana, podemos entonces resolver nuestra orientación metódica hacia la comprensión de la salvación como visión de Dios. A esto intentaremos avocarnos.

\section{La economía de la salvación en el ver a Dios}

Entramos ya a la última parte de nuestra breve aproximación. Podemos reconocer cómo nuestro autor, en su defensa de la ortodoxia, y dada su búsqueda, nos propone ideas claras respecto del acontecimiento salvífico. El «ver» de los profetas, del cual hemos hablado más arriba, nos invita entonces a comprender la salvación: como esta concreción que acontece en el Verbo encarnado, pues es él, el Verbo, quien habría de unir el fin al principio, el hombre a Dios. No obstante, según hemos señalado, antes de encarnarse se deja sentir entre los justos, otorgándoles el carisma profético. Es el todo de la economía de la salvación que

\footnotetext{
53 Sed secundum magnitudinem quidem eius et inenarrabilem gloriam nemo widebit Deum et wiuet, incapabilis enim Pater, secundum autem dilectionem et humanitatem et quod omnia possit, etiam hoc concedit his qui se diligunt, id est uidere Deum, quod et prophetabant prophetae (Adv. Haer. 20,5).

54 A. OrBE: Teología de San Ireneo, 288.
} 
acontece en el ver a Dios, ver que se hace posible según su amor, pues como nos recuerda el mismo Ireneo, según su grandeza no lo podemos conocer $^{55}$.

Es la idea que desde el principio el Padre se ha revelado a quien quiere, cuando quiere y como quiere, por medio de su Hijo, que es su Palabra ${ }^{56}$. Por tanto, aquellos que desde siempre, como partícipes de una misma economía, han creído en la Palabra de Dios - tanto en el Antiguo Testamento como en el Nuevo Testamento- han creído en Cristo, y por la fe en él se han salvado. De este mismo modo aquellos que se salvaron por la Ley también participan de este acontecimiento salvador. Pues para Ireneo es claro que la ley que fue dada por el Verbo en el Antiguo Testamento, resulta ser una especie de pedagogía de la Ley Nueva ${ }^{57}$. El ver de los profetas se relaciona entonces directamente con el Hijo, porque sólo en el Hijo tenemos acceso al Padre desde el principio, por tanto el carácter salvador que acontece en el Hijo es único ${ }^{58}$.

El Hijo, en cuanto Verbo, manifestó ya desde el Antiguo Testamento, más aún desde la creación ${ }^{59}$; la revelación que acontece progresivamente en la historia, que culmina con la encarnación de la misma Palabra, para seguir mostrando a Dios en la carne y llamarlo su Padre $^{60}$. En definitiva, Dios es glorificado por su Verbo, que es su Hijo para siempre, y por el Espíritu Santo, que es la Sabiduría del Padre de

55 Et propter hoc incapabilis et incomprehensibilis <et inuisibilis> wisibilem se et comprehensibilem et capacem hominibus praestat, ut vinificet percipientes et videntes se (Adv. Haer. IV 20,5).

56 Neque enim Patrem cognoscere quis potest sine Uerbo Dei, hoc est nisi Filio reuelante, neque Filium sine Patris beneplacito. Bonum autem placitum Patris Filius perficit: mittit enim Pater, mittitur autem et uenit Filius. Et Patrem quidem inuisibilem et indeterminabilem, quantum ad nos est, cognoscit suum ipsius Uerbum, et cum sit inenarrabilis, ipse enarrat eum nobis; rursus autem Uerbum suum solus cognoscit Pater (Adv. Haer. IV 6,3).

57 Ne ergo in eandem poenam cum his ueniamus, finem eorum ostendit Dominus, simul significans quod obaudientes Moysi et prophetis crederent in eum quem ipsi praedicassent Filium Dei, qui resurrexit a mortuis et uitam nobis donat, et demonstrat ex una substantia esse omnia, id est Abraham et Moysen et prophetas, etiam ipsum Dominum qui resurrexit a mortuis, in quem et credunt multi qui sunt a circumcisione, qui et Moysen et prophetas audiunt praedicantes aduentum Filii Dei; qui autem spernunt et ab altera substantia eos esse dicunt, neque primogenitum mortuorum sciunt, separatim Christum intellegentes, tamquam impassibilem perseue rantem, et separatim eum qui passus est Iesum (Adv. Haer. IV 2,3).

58 Et ideo scribae et Pharisaei, qui coeperant a temporibus legis contemnere Deum, nec Uerbum eius receperunt, id est non crediderunt Christo (Adv. Haer. 2,6).

59 Etenim per ipsam conditionem reuelat Uerbum Conditorem Deum, et per mundum Fabricatorem mundi Dominum, et per plasma eum qui plasmauerit artificem, et per Filium eum Patrem qui generauerit Filium; et haec omnes similiter quidem colloquuntur, non autem similiter credunt (Adv. Haer. 6,6).

60 Llama la atención esta relación que Ireneo postula tan radicalmente (perichóresis), ya que al revelarse el Verbo a sí mismo en su carne, en esa misma revelación como Hijo, el Señor revela al Padre (Adv. Haer. IV, 6,3.5.7). Y hace posible el ver profético: «Pues lo invisible del Hijo es el Padre, y lo visible del Padre es el Hijo» (Adv. Haer. IV 6,6). 
todas las $\operatorname{cosas}^{61}$. Ireneo habla del Espíritu como la Sabiduría, pues es el Espíritu el que da la forma, la armonía, la semejanza de Dios a todo el orden creado. «Es el Espiritu el que habia dado la figura a lo creado, de modo que bablar en figura o figuradamente es hablar bajo el influjo del Espiritu que es la figuratio Patris $\rangle^{62}$. En este sentido el ver de los profetas se traduce en el hecho que ellos, por un don especial, han manifestado aquello que vieron (figuraliter), a saber, la diversidad de carismas; las economías del Verbo; la gloria del Padre. Los profetas han conocido la Revelación de Dios Padre (entiéndase revelación trinitaria).

Resumiendo, ¿cómo es posible, entonces, que el hombre pueda ver a Dios? La respuesta a esta pregunta tiene que ver, no con el hecho de que el hombre pueda ver a Dios, sino que es Dios quien se deja ver por el hombre, pues es el mismo Dios quien ha de sostener al hombre en régimen de visión, mediante la comunicación a él de su misma vida ${ }^{63}$. Es esta vida, la divina, la que otorga la salvación al hombre y esta salvación es sostenida por Dios, «de Dei participatione». Participación y comunión de vida con Dios, esto es ver a Dios.

\section{Fundamentación profética del acontecimiento salvífico (significans quod futurum erat)}

Retomando el tema de la profecía que, como hemos visto reviste en el Lugdunense un carácter esencial, fruto de la acción trinitaria ${ }^{64}$. Debemos señalar que ella, en cuanto don del Espíritu, es la que hace posible descubrir al único Dios y a su vez reconocerlo y llamarlo Señor. También reveló que Dios es Padre e Hijo, y que los seres humanos fuimos creados para llegar a ser un día hijos de Dios participando de la filiación del Hijo. Con esto podemos afirmar una nueva perspectiva que Ireneo nos ofrece, a saber, que el ministerio profético no se limita al mero anuncio de las cosas futuras, lo que ya es bastante decir, sino que la perspectiva del Lugdunense solicita la salvación ${ }^{65}$. Más aún, la salvación

\footnotetext{
61 Propter hoc Indaei excesserunt a Deo, Uerbum eius non recipientes, sed putantes per seipsum Patrem sine Uerbo, hoc est sine Filio, posse cognoscere Deum, nescientes eum qui in figura locutus est bumana ad Abraham, et iterum ad Moysen, dicentem: Uidens vidi uexationem populi mei in Aegypto, et descendi liberare eos.

62 R. POLANCO: El concepto de profecía en la teología de San Ireneo, 34.

63 A. OrBE: Teología de San Ireneo, 291.

64 Pues es en el Padre tiene su origen, el Espíritu Santo inspira a los hombres elegidos y habla por ellos para preparar la venida del Hijo en la carne.

65 Quoniam ergo Spiritus Dei per prophetas futura significanit, praeformans nos et praeaptans ad id ut subditi Deo simus, futurum autem erat ut homo per sancti Spiritus beneplacitum videret $<$ Deum $>$,
} 
de la que nos habla Ireneo no sólo nos permite conocer ${ }^{66}$, pues la salvación no se reduce a la mente, sino que sobre todo se dirige a santificar al hombre, para que ame a Dios y amándole le dé gloria. Así toda la actividad profética perseguirá este fin, es decir, anunciar la encarnación y el cumplimiento de la economía del Padre mediante la carne de su Hijo.

La relación entre la misión profética queda esbozada en la acción permanente del Espíritu en esta misma economía, la vocación profética se hace posible por este Espíritu: el Espíritu es quien ha guiado a los justos por el camino de la fe y de la justicia, es el que ha repartido a los antiguos padres, en herencia, la tierra prometida ${ }^{67}$. Es este mismo Espíritu el que habló por los profetas. La visión, entonces, es tenida proféticamente gracias a la acción del Espíritu ${ }^{68}$ que siempre ha actuado en una misma economía.

Un texto clave en esta comprensión, que sintetiza muy bien la acción profética de cara a la salvación, lo encontramos en el 20,8 del cuarto libro: «Quoniam ergo Spiritus Dei per prophetas futura significanit, praeformans nos et praeaptans ad id ut subditi Deo simus, futurum autem erat ut homo per sancti Spiritus beneplacitum uideret $<$ Deum $>$, necessario oportebat eos per quos futura praedicabantur videre Deum, quem ipsi hominibus videndum intimabant, uti non solum dicatur prophetice Deus et Dei Filius et Filius et Pater, sed et ut videatur omnibus membris sanctificatis et edoctis ea quae sunt Dei, ut praeformaretur et praemeditaretur homo applicari in eam gloriam quae postea reuelabitur his qui diligunt Deum» ${ }^{69}$. Es en este texto en donde se caracteriza más

necessario oportebat eos per quos futura praedicabantur uidere Deum, quem ipsi hominibus uidendum intimabant, uti non solum dicatur prophetice Deus et Dei Filius et Filius et Pater, sed et ut videatur omnibus membris sanctificatis et edoctis ea quae sunt Dei, ut praeformaretur et praemeditaretur homo applicari in eam gloriam quae postea reuelabitur his qui diligunt Deum (Adv. Haer. IV 20,8).

66 Señalemos que para el gnóstico la «salvación» consistía en un conocimiento de Dios: los seres materiales no pueden salvarse porque jamás conocerán la Verdad; a los psíquicos les queda la esperanza de vencer sus pasiones y de ser instruidos por los gnósticos en la doctrina del Dios desconocido (Adv. Haer. I, 6,2). Los espirituales (pneumáticos) ya están salvados por naturaleza, por la gnosis del Dios desconocido.

67 Propheta ergo cum esset Abraham et videret in Spiritu diem aduentus Domini et passionis dispositionem, per quem ipse quoque et omnes qui similiter ut ipse credidit credunt Deo saluari inciperent, exsultauit uehementer (Adv. Haer. IV 5,5).

68 (...) potens est enim in omnibus Deus, uisus quidem tunc per Spiritum prophetice, uisus autem et per Filium adoptiue (...) (Adv. Haer. IV 20,5).

69 Por tanto: ya que el Espiritu de Dios anunció el futuro mediante los profetas, preparándonos y moldeándonos de antemano para esto; para que seamos obedientes a Dios pues habia de suceder que el hombre, por beneplácito del Espiritu Santo, contemplase (a Dios). Pues era necesario que quienes habian de predicar las cosas futuras, contemplasen a Dios, era absolutamente necesario que aquellos por medio de los cuales el futuro era anunciado, vieran al Dios que ellos mismos anunciaban que sería visto por los hombres. Y lo habrian de hacer de modo que no sólo se hablase proféticamente de Dios y del 
patentemente la clave espiritual en la acción profética. Pues estos, los profetas, ya han experimentado la visión. El Espíritu Santo ha actuado en los profetas revelándoles el futuro, en este preparar va modelándolos y configurándolos para ello. Lo que hace posible que la acción de este mismo Espíritu deje su huella en quien actúa, es decir, en los profetas. Ellos experimentaban en sí mismos lo que habría de venir, por esto es que el Lugdunense deduce (contra el mundo gnóstico) que el conocimiento de Dios no será experiencia de una parte del hombre, sino que será una visión que implicará a todo el hombre. «Por eso el profeta ve a Dios con toda su bumanidad» ${ }^{70}$.

\section{Participación de Dios como salvación y visión (salus et videor)}

La visión de Dios ya ha tomado consistencia en nuestro autor, y la clave profética nos ha introducido en la salvación, de la cual los profetas del Antiguo Testamento ya participaban, pues Jesús reveló a un solo Padre, el mismo Creador del universo. Es este mismo Espíritu el que ha revelado al Padre y dispuso el camino a la venida del Hijo mediante la inspiración profética, «preparando al hombre para el Hijo de Dios» ${ }^{71}$. Aquí nuestro autor da un nuevo paso en su comprensión de la salvación, pues si bien el Espíritu había actuado proféticamente, ahora es el Hijo el que adoptivamente hace posible la misma visión. El Espíritu prepara y el Hijo viene a donar lo que estaba incompleto, de un modo adoptivo ${ }^{72}$.

La visión de Dios conducente a la salvación queda, entonces, afianzada aquí en la acción del Espíritu y el Hijo. «En efecto, si los profetas han adelantado en su vida lo que será el futuro conocimiento de Dios, al ser santificados por la obra del Espíritu y adoctrinados por el ministerio del Verbo, sus profecías han de ser también de diferentes formas para expresar esta riqueza que implica el ver a Dios» ${ }^{73}$.

Hijo de Dios, del Hijo y del Padre; sino para que también sea percibido por todos los miembros enseñados y santificados; para que el hombre fuese educado y meditase cómo disponerse para la gloria que habría de revelarse a quienes aman a Dios (la traducción es mía).

70 R. POLANCO: El concepto de profecía en la teología de San Ireneo, 41.

71 Adv. Haer. IV 20,5.

72 Homo etenim a se non videbit Deum; ille autem nolens videbitur hominibus, quibus uult et quando uult et quemad modum uult: potens est enim in omnibus Deus, uisus quidem tunc per Spiritum prophetice, uisus autem et per Filium adoptiue, uidebitur autem et in regno caelorum paternaliter, Spiritu quidem praeparante hominem in Filium Dei, Filio autem adducente ad Patrem, Patre autem incorruptelam donante in aeternam nitam, quae unicuique euenit ex eo quod uideat Deum (Adv. Haer. IV 20,5).

73 R. POLANCO: El concepto de profecía en la teología de San Ireneo, 41. 
Este acontecimiento, anclado ya en las dos personas divinas, conduce ahora al Padre que concede en el Hijo (paternaliter) la visión definitiva del Reino. Aquí el Lugdunense pone de relieve una vez más, y con certera afirmación, el acontecimiento salvífico que se constituye en una sola economía: Proféticamente (a través del Espíritu), adoptivamente (por medio del Hijo), Paternalmente (en el Hijo al Padre). La economía de la salvación se ve ratificada aquí en la Trinidad.

Las tres fases, según el proceso histórico, de la humana habilitación a la vista de Dios Padre, se anunciaban ya entre los profetas del Antiguo Testamento. Los que ven a Dios perciben así de este modo la vida, pues el inalcanzable, invisible e incomprensible, se hace alcanzable, visible y comprensible por su inefable amor ${ }^{74}$. La visión de Dios se transforma de este modo en salvación, pues la subsistencia de la vida viene por participar de Dios y participar de Dios es ver a Dios.

\section{Conclusión}

Hemos intentado realizar un recorrido breve por la obra de Ireneo, Adversus Haereses, en ella hemos querido quedarnos, para profundizar en la comprensión de la salvación, entendida esta como visión de Dios. De entre todo lo antes señalado nos parece relativamente claro que la predicación apostólica para el Lugdunense, junto a la enseñanza del Señor, el anuncio de los profetas y el servicio de la Ley, manifiestan a un solo Dios de todas las cosas, alaban al Padre, y - contra los gnósticosno se refieren a varios dioses, ni dicen que éstos hayan sido emitidos por otros dioses y potencias, sino del único y mismo Padre de todas las cosas. Por tanto, será la vista directa e inmediata de este único Padre la que otorga a la carne la incorruptela, esta es la visión profética que prevalece en nuestro autor. La visión que los profetas destacan en figura, se hace patente para el agraciado que se ha dejado penetrar por el Espíritu, que es el único capaz de hacernos inmortales por la comunión con el Padre.

Los profetas del Antiguo Testamento entran de este modo en la salvación. Ellos han participado ya de la visión de Dios, por lo que perfectamente acceden a las enseñanzas del Verbo. La economía trinitaria de la salvación, que se entiende aquí como parte de un único designio, permite sostener esta afirmación y abrir camino a la misma Trinidad. Pero es ante todo la Encarnación, la que hace posible ver a

\footnotetext{
74 Et propter hoc incapabilis et incomprehensibilis <et inuisibilis> nisibilem se et comprehensibilem et capacem hominibus praestat, ut nivificet percipientes et videntes se (Adv. Haer. IV 20,5).
} 
Dios. La subsistencia de la vida viene entonces por la participación de Dios, pero la participación de Dios es ver a Dios y gozar de la bondad de él.

Sumario: Introducción; 1. Salvación y visión: conceptos; 2. Contexto inmediato del tema: situación antignóstica; 3 . La salvación como prioridad Ireneana; 4. La comprensión del ver en un modo figurado (presignificatio); 5. La operación profética (video-visio); 6. La economía de la salvación en el ver a Dios; 7. Fundamentación profética del acontecimiento salvífico (significans quod futurum erat); 8. Participación de Dios como salvación y visión (salus et videor); Conclusión. 